\section{REFERENCES}

A VERBACH, E., \& SPERLING, G Short-term storage of information in vision. In R. N. Haber (Ed.) Contemporary theory and research in visual perception. New York: Holt Rinehart. \& Winston, 1968. Pp. 202-214.

BAKER, C, H. Location preferences when choice is forced. Perceptual \& Motor Skills, 1963, 16, 746.

BRY DEN, M. P. A model for the sequential organization of behavior. Canadian Joumal of Psychology, 1967, 21, 37-56.

CLEMENT, D. E., \& HOSKING, K. E Scanning strategies and differential sensitivity in a visual signal detection task: Intrasubject reliability. Psychonomic Science, 1971, 22, 323-324.

CROVITZ, H. F., \& SCHIFFMAN, H. R. Visual field and the letter span. Journa of Experimental Psychology, 1965, 70 218-223.

ENOCH,J. M. Effect of the size of a complex display upon visual search Journal of the Optical Society of America. 1959, 49, 280-286.

ESTES, W K \& TAYLOR, H A Visual detection in relation to display size and redundancy of critical elements. Perception \& Psychophysics, 1966, 1 9-16.

FORD, A.. WHITE, C. T. \& LICHTENSTEIN, M. Analysis of eye movements during free search. Journal of the Optical Society of America, 1959, 49 287-292.

GREEN, D. M., \& SWETS, J. A. Signal detection theory and psychophysics. New York: Wiley, 1966.

HERON, W. Perception as a function of retinal locus and attention. American Journal of Psychology, 1957, 70, 38-48

HERSHENSON, M. Stimulus structure cognitive structure, and the perception of letter arrays. Journal of Experimental Psychology , 1969, 79, 327-335.

HOLMGREN, J. Visual detection with imperfect recognition. T. R. No. 128 ,
March 1968, Institute for Mathematical Studies in the Social Sciences, Stanford University, Stanford, California.

KRUEGER. L. E. Effect of duration of sequential presentation and redundancy on short-term recognition memory. Perception \& Psychophysics, 1971, 9, 121-124.

LINCOLN, R. S., \& AVERBACH, E. Spatia factors in check reading of dial groups. Journal of Applied Psychology, 1956, 40. 105-108.

MACKWORTH, N. H. Visual noise cause tunnel vision. Psychonomic Science, $1965,3,67-68$

NOTON, D., \& STARK, L. Scanpaths in eye movements during pattern perception Seience, 1971, 171, 308-311.

SCHISSLER, D \& BARATTA, M An addition to the reading scan hypothesis. Paper presented at Psychonomic Society meeting, San Antonio, 1970

SWETS, J. A. (Ed.) Signal detection and recognition by human observers Contemporary readings. New York Wiley, 1964

TAYLOR, H. A. Context and learning in the processing of information from brie visual displays. Perception \& Psychophysics, 1970, 7, 15-18

VOLKMANN, J., \& CORBIN, H. H. Further experiments on the rage of visual search. USAF ESD TDR No. 65-169, 1965.

VOLKMANN, J., CORBIN, H. H., EDDY N. B., \& COONLEY, C. The range of visual search. USAF ESD TDR No. 64-535, 1964

WHITE, M. J. Retinal locus and the letter-span error function. Perception \& Psychophysics, 1970, 8, 107-109.

WHITE, C. T., \& FORD, A. Eye movements during simulated radar search. Journal of the Optical Society of America, 1960,50, 909-913.

WINNICK, W. A., \& BRUDER, G. E. Signal detection approach to the study of retinal locus in tachistoscopic recognition. Journal of Experimental Psychology $1968,78,528-531$

\title{
Identification of olfactory dimensions by semantic differential technique
}

\author{
MARK CUNNINGHAM and CAROL A. CRADY \\ Murray State University, Murray, Ky. 42071
}

Twenty Ss rated 14 odorants on 24 semantic differential scales. Scale scores for each odorant were obtained as the median rating across Ss. Factor analysis yielded four interpretable dimensions of olfactory perception.

For use in a study on olfactory adaptation, the authors needed to scale odorants along subjectively meaningful dimensions. The archives contain many works on the dimensionality of olfactory experience, but they show much dissimilarity. A study by Yoshida (1964), in which the semantic differential technique was used to find olfactory dimensions in a Japanese population, seemed to offer the best approach for the projected studies. The study here reported was an extension of Yoshida's (1964) study and was designed to identify subjective olfactory dimensions in American college students.

\section{SUBJECTS}

Ten male and 10 female volunteers from an introductory psychology class served as Ss. They were not anosmic, were not suffering infections which would impair olfactory sensation, and were not wearing any cologne or lotions.

Fourteen odorants (Table 1), chosen to represent a wide variety of qualitative classifications, particularly the categories of Shultz (1964), were used in the study. The odorants were contained in stoppered $13 \times 100 \mathrm{~mm}$ test tubes, taped at the bottom to reduce visual cues. Each test tube contained approximately $3 \mathrm{cc}$ of odorant.

Twenty-four adjectival scales were used for $\mathrm{S}$ ratings. Each of the scales was a bipolar 7-point rating scale (Table 2). Twelve of these scales were taken from Yoshida (1964) because they appeared most applicable to odor scaling. The other 12 were chosen randomly from 76 scales found reliable in previous semantic differential experiments (Osgood, Suci, \& Tannenbaum, 1957). The 24 scales appeared on a single sheet; the order of scales and position (left-right) of the adjectives in each scale were determined randomly. Position of the adjectives was reversed for half the Ss. A separate sheet was used for each S's rating of each odor.

\section{PROCEDURE}

The Ss were run individually, seated at a table in an air-conditioned laboratory room. An electric fan was used to circulate air in the immediate area.

Each $\mathrm{S}$ was instructed in the use of the semantic differential scales, then handed the first test tube. The $S$ was allowed to keep the tube, smelling the odorant as necessary during the time he was marking the 24 scales. A 3 -min interval preceded presentation of the following odorants.

\section{RESULTS}

The obtained data were in the form of a 20 (Ss) by 14 (odorants) by 24 (scales) matrix of ratings. The data were reduced to a 14 by 24 table by obtaining a median rating across Ss. These medians were then used as odorant scores on the 24 scales. Pearson rs were computed for each pair of scales. Factor analysis, using a Varimax rotation, yielded the factor loadings presented in Table 2.

$$
\text { DISCUSSION }
$$

It is indicated in Table 2 that a single factor accounted for a very large part of the responses to the odorants. This factor, which accounted for $51 \%$

Table 1

Odorants Rated

\begin{tabular}{ll} 
Ammonia & Crotonic Acid \\
Amyl Acetate & Dodecanethiol \\
Amyl Alcohol & Milk of Asafoetida \\
Banana Oil & Oil of Sassafras \\
Benzaldehyde & Pentene \\
Butanol & Pyridine \\
Butyric Acid & Solution of Coal Tar \\
\hline
\end{tabular}


Table 2

Rotated Varimax Factor Loadings on the 24 Scales

\begin{tabular}{|c|c|c|c|c|c|c|c|c|}
\hline \multirow[b]{2}{*}{ Scales } & \multicolumn{8}{|c|}{ Factors } \\
\hline & I & II & III & IV & $\mathbf{V}$ & VI & VII & VIII \\
\hline Good-Bad & .95 & .19 & -.11 & -.10 & .07 & -.08 & -.11 & .13 \\
\hline Sociable-Unsociable & .90 & .22 & -.08 & -.21 & .24 & -.09 & -.08 & .03 \\
\hline Light-Dark & .74 & .41 & -.35 & -.28 & .19 & -.17 & -.16 & .02 \\
\hline High-Low & .34 & .85 & -.16 & -.14 & -.11 & -.14 & -.05 & -.03 \\
\hline Negative-P ositive & -.90 & -.17 & .31 & .03 & -.18 & .05 & .13 & .03 \\
\hline Soft-Hard & .82 & .13 & -.02 & -.32 & .37 & -.10 & .02 & -18 \\
\hline Spacious-Constricted & .80 & .21 & -.20 & -.12 & -.07 & -.07 & -.39 & .00 \\
\hline Masculine-Feminine & -.78 & -.09 & .25 & -.18 & -.22 & .32 & -.06 & .04 \\
\hline Slow-Fast & .16 & -.74 & -.03 & -.21 & .05 & -.09 & -.08 & .04 \\
\hline Sane-Insane & .90 & -.03 & -.16 & -.25 & .15 & .17 & .04 & .02 \\
\hline Sharp-Blunt & -.05 & .95 & -.05 & .20 & -.04 & -.05 & .05 & .00 \\
\hline Refreshed-Weary & .60 & .52 & -.45 & -.20 & .11 & -.18 & -.24 & .10 \\
\hline Inherent-Extraneous & .34 & -.10 & -.17 & -.04 & .69 & -.01 & -.02 & .01 \\
\hline Periodic-Erratic & .93 & -.06 & -.16 & -.18 & .17 & .15 & .03 & -.09 \\
\hline Cold-Hot & .26 & .66 & -.18 & .09 & .17 & .10 & -.35 & .04 \\
\hline Rough-Delicate & -.91 & -.11 & .22 & .21 & -.20 & .08 & .04 & -.00 \\
\hline Clean-Dirty & .63 & .45 & -.44 & -.37 & .19 & .11 & -.07 & -.09 \\
\hline Light-Heavy & .56 & .46 & -.54 & -.34 & .09 & .02 & -.18 & -.03 \\
\hline Sour-Sweet & -.80 & -.00 & .40 & -.37 & -.10 & -.11 & -.10 & .00 \\
\hline Peaceful-Violent & .83 & -.07 & -.24 & -.26 & .23 & .04 & -.04 & .30 \\
\hline Passive-Active & .48 & -.25 & -.01 & -.61 & -.07 & -.02 & -.21 & .23 \\
\hline Temporary-Long Lasting & .45 & .19 & -.64 & -.12 & .44 & .04 & -.01 & -.01 \\
\hline Thick-Thin & -.48 & -.52 & .48 & -.10 & -.33 & .11 & .02 & -.07 \\
\hline Anesthetic-Stimulant & .19 & -.25 & -.11 & -.77 & .07 & .02 & .07 & -.07 \\
\hline Percent Common Variance & $\mathbf{5 1 \%}$ & $18 \%$ & $10 \%$ & $9 \%$ & $6 \%$ & $2 \%$ & $3 \%$ & $1 \%$ \\
\hline
\end{tabular}

of the common variance, represents a dimension of attraction, evaluation, or as named by Yoshida (1964), sensory pleasure. This factor loads such scales as "good," "positive," "sane," "periodic," and "delicate." This dimension arises in one form or another in all odor classification schemes. It is also relevant to common experience in which the "goodness" or "badness" of an odor is frequently the first qualitative discrimination made. Odorants rated toward the "good" end of scales loading on this factor were amyl acetate and benzaldehyde. Some of those which were rated toward the "bad" end were butyric acid, pyridine, and dodecanethiol. As a generalization, it may be said of human response to odor that the most predictable element is that of affective judgment.

The second factor, accounting for $18 \%$ of the common variance, loaded such scales as "sharp," "high," "fast," "hot," and "stimulating." The quality of alfaction tapped by this factor might be called "vividness," to use another label from Yoshida (1964), or perhaps "sharpness." It may also be suggested that this factor represents a strength or potency dimension. However, on those scales usually associated with potency in verbal concept rating studies, here represented only by "light" and "masculine," this factor drew only moderate to low loadings. Similarly, "activity" was not considered because of the low loading of "active" on this second factor and a higher loading of "active" on the fourth factor. The scale loading on this factor leads to a suggestion that this factor is reflecting a trigeminal component of olfactory sensation. Odorants rated very highly on scale loading on this factor are represented by pyridine, benzaldehyde, and amyl alcohol.

The third factor, which accounted for $10 \%$ of the common variance, loaded such scales as "heavy," "thick," and "long-lasting." Odorants judged to have these characteristics were benzaldehyde and banana oil. This dimension appears to represent a pervasive or durable characteristic of odors. Such a dimension would probably be found important in any heavy musky odor.

The relatively high loadings of "active" and "stimulant" on the four factor, which accounted for $9 \%$ of the common variance, suggest a dimension of "activity" that is distinct from the "sharp" connotation of the second factor. Odorants rated highly active and stimulating were butyric acid and pyridine. The remaining factors accounted for relatively little common variance.

This initial study indicates, in replication of Yoshida (1964), that the semantic differential is a worthy tool for the identification of subjective dimensions of olfactory quality and that it may serve as a basis of attempts to scale those qualities. Additional studies with a larger variety of odorants and a much larger selection of scales are indicated to identify factors better. It would also be of interest to learn whether or not these factors remain stable across a wide range of stimulus intensities and presentation intervals.

\section{REFERENCES}

OSGOOD, C. E., SUCI, G. J., \& TANNENBAUM, P. H. The meosurement of meaning. Urbana: University of Illinois Press, 1957.

SHULTZ, H. G. A matching-standards method for characterizing odor qualities. Annals of the New York Academy of Sciences, 1964, 116, 517-525.

YOSHIDA, M. Studies in psychometric classification of odors. Japanese Journal of Psychology, 1964, 35, 1-17. 